\title{
Anuncios y próximos números
}

\section{PRÓXIMOS NÚMEROS}

\section{1 (1) 31 de enero de 2018.}

El número que publicaremos en enero de 2018 será un número misceláneo que recogerá trabajos presentados en la II Conferencia Ibérica de Sociología de la Educación celebrada los días 13 y 14 de julio de 2017, tal y como se anunció en el congreso. La RASE ya ha recibido varias contribuciones para este número.

\section{1 (2) 31 de mayo de 2018.}

Este monográfico titulado "Biograficidad y educación" y coordinado por $\mathrm{M}^{\mathrm{a}}$ Eugenia Cardenal de la Nuez y Francesc J. Hernàndez pretende reunir contribuciones enmarcadas en el análisis de las biografías y los procesos educativos y formativos. En el contexto europeo se están desarrollando trabajos de índole teórica y empírica en los que se relaciona el análisis de las biografías y la formación. En ese sentido, la vida es inseparable de su relato, y ese nexo permite redefinir la noción de aprendizaje y la toma de decisiones educativas. De hecho, los procesos educativos pueden comprenderse como decisiones en el curso de la vida y, por tanto, cargados de biograficidad. Este monográfico publicará trabajos que aborden esta perspectiva y que traten la noción de biografía en su uso científico para el campo educativo. 